Research Article

\title{
Crystal Structure and Catalytic Activity of Poly[bis(3-bromo-2-hydroxybenzaldehyde)-2- aminopyrimidinemagnesium(II)] for Hydrogenation of 1,3-Butadiene
}

\author{
Li-Hua Wang, Fan-Yuan Kong, Xi-Shi Tai*
}

College of Chemistry and Chemical Engineering, Weifang University, Weifang 261061, P. R. China.

Received: $19^{\text {th }}$ February 2021; Revised: 28th April 2021; Accepted: $28^{\text {th }}$ April 2021

Available online: $2^{\text {nd }}$ May 2021; Published regularly: June 2021

\begin{abstract}
A new six-coordinated $\mathrm{Mn}(\mathrm{II})$ coordination polymer, $\left[\mathrm{Mn}\left(\mathrm{L}_{1}\right)\left(\mathrm{L}_{2}\right)_{2}\right]_{\mathrm{n}}\left(\mathrm{L}_{1}=2\right.$-aminopyrimidine, HL $\mathrm{L}_{2}=3$-bromo-2hydroxybenzaldehyde) was synthesized by 3-bromo-2-hydroxybenzaldehyde, $\mathrm{NaOH}, 2$-aminopyrimidine and manganese(II) acetate dihydrate. The Mn(II) coordination polymer was structural characterized by elemental analysis and single crystal X-ray diffraction. The results show that each $\mathrm{Mn}$ (II) ion is six-coordinated with two phenolic hydroxyl $\mathrm{O}$ atoms from two 3-bromo-2-hydroxybenzaldehyde ligands (O1 and $\mathrm{O} 4$ ), two formyl group $\mathrm{O}$ atoms from two 3-bromo-2-hydroxybenzaldehyde ligands (O2 and $\mathrm{O} 3$ ), and two $\mathrm{N}$ atoms from two 2-aminopyrimidine molecules (N1A and N2), and forms a distorted octahedral coordination geometry. The Mn(II) coordination polymer displays a $1 \mathrm{D}$ chained structure by the bridge effect of 2 -aminopyrimidine $\mathrm{N}$ atoms. The catalytic activities of $\mathrm{Mn}$ (II) coordination polymer and Pd@Mn(II) coordination polymer for hydrogenation of 1,3-butadiene have been investigated. The Pd@Mn(II) coordination polymer catalyst shows the good catalytic activity and selectivity in the hydrogenation of 1,3 -butadiene. The 1,3 -butadiene conversion is $61.3 \%$ at $70{ }^{\circ} \mathrm{C}$, and the selectivity to total butene is close to $100 \%$.
\end{abstract}

Copyright (C) 2021 by Authors, Published by BCREC Group. This is an open access article under the CC BY-SA License (https://creativecommons.org/licenses/by-sa/4.0).

Keywords: Mn (II) coordination polymer; Synthesis; Structural characterization; Catalytic activity

How to Cite: L.H. Wang, F.Y. Kong, X.S. Tai (2021). Crystal Structure and Catalytic Activity of Poly[bis(3-bromo2-hydroxybenzaldehyde)-2-aminopyrimidinemagnesium(II)] for Hydrogenation of 1,3-Butadiene. Bulletin of Chemical Reaction Engineering \& Catalysis, 16(2), 260-266 (doi:10.9767/bcrec.16.2.10421.260-266)

Permalink/DOI: https://doi.org/10.9767/bcrec.16.2.10421.260-266

\section{Introduction}

In the petrochemical industry, the thermal cracking of petroleum fractions usually produces the byproduct 1,3 -butadiene (1,3-BD), which must be removed below $10 \mathrm{ppm}$ for polymerization processes because they poison the catalysts and degrade the product quality [1]. The hydro-

* Corresponding Author.

Email: taixs@wfu.edu.cn (X.S. Tai);

Telp: +86-536-8785363, Fax: +86-536-8785363 genation of 1,3-butadiene is an effective strategy to remove 1,3-butadiene in the in the petrochemical industry. $\mathrm{Pd}$ supported catalyst is mostly used in the selective hydrogenation of 1,3-butadiene due to the excellent catalytic activity, selectivity, and stability [2,3]. Manganese coordination polymers exhibit excellent activity in many fields, such as: catalytic property [4-7], magnetic properties [8-11], solvent adsorption [12], oxidative dehydrogenation [13], antitumor and antibacterial activities [14,15], lumines- 
cence properties [16-19], electrochemical property [20], and nonlinear optical property [21] and so on. So the researches on the manganese coordination polymer have attracted the attention of scientists. The synthesis of coordination polymers is influenced by ligands, metal centers, solvent, $\mathrm{pH}$ and reaction temperature [22]. In addition, the mixed ligands has become an impactful factor in the formation of coordination polymers.

However, there are few studies on hydrogenation of 1,3-butadiene catalyzed by manganese coordination polymers. Our research group has studied the catalytic activity of some metal complexes [23-28]. To further explore the catalytic activity of metal complexes, in this paper, a novel Mn(II) coordination polymer has been synthesized by 3-bromo-2hydroxybenzaldehyde, $\mathrm{NaOH}, \quad 2$ aminopyrimidine and manganese(II) acetate dihydrate. The structure of $\mathrm{Mn}$ (II) coordination polymer has been determined by elemental analysis and single crystal X-ray diffraction. The catalytic activities of $\mathrm{Mn}$ (II) coordination polymer and Pd@Mn(II) coordination polymer for hydrogenation of 1,3-butadiene have been investigated. The $\mathrm{Pd}$ nanoparticles were loaded on the surface of $\mathrm{Mn}$ (II) coordination polymer, and the catalytic active center of Pd can be completely exposed to the reactants of 1.0 vol\%1,3-butadiene/ $\mathrm{N}_{2}$ and $\mathrm{H}_{2}$. Furthermore, the catalytic activity is not affected by the size of reactants. Interestingly, the $\mathrm{Mn}$ (II) coordination polymer catalyst exhibits very low catalytic activity with 1,3-butadiene conversion less than $1 \%$ toward the 1,3-butadiene hydrogenation, however, the $\mathrm{Pd} @ \mathrm{Mn}$ (II) coordination polymer catalyst shows the higher conversion $(61.3 \%$ at $70^{\circ} \mathrm{C}$ ) than $\mathrm{Mn}(\mathrm{II})$ coordination polymer.

\section{Materials and Methods}

\subsection{Materials and Measurements}

3-bromo-2-hydroxybenzaldehyde (A.R.), $\mathrm{NaOH}$ (A.R.), 2-aminopyrimidine (A.R.), and manganese(II) acetate dihydrate (A.R.) were purchased from Jilin Chinese Academy of Sciences-Yanshen Technology Co., Ltd.. C, $\mathrm{H}$ and $\mathrm{N}$ were analyzed using an Elementar Vario III EL elemental analyzer (Hanau, Germany). The crystal data of $\mathrm{Mn}$ (II) coordination polymer were collected on a Bruker Smart CCD diffractometer (Bruker, Billerica, MA, USA). The effluent from the reactor was collected and analyzed using an online gas chromatography (GC6890, Purkinje General Instrument Co., Ltd., China) equipped with a $\mathrm{Al}_{2} \mathrm{O}_{3}$ capillary column.

\subsection{Synthesis of $\mathrm{Mn}(\mathrm{II})$ Coordination Polymer}

The 3-bromo-2-hydroxybenzaldehyde (0.5 mmol, $0.1005 \mathrm{~g}), 2$-aminopyrimidine $(0.5 \mathrm{mmol}$, $0.4750 \mathrm{~g})$ and $\mathrm{NaOH}(0.5 \mathrm{mmol}, 0.020 \mathrm{~g})$ were dissolved in $15 \mathrm{~mL}$ ethanol $/ \mathrm{H}_{2} \mathrm{O}$ solution (v:v = $2: 1$ ) with stirring. After $1 \mathrm{~h}, 0.0865 \mathrm{~g}$ manganese(II) acetate dihydrate $(0.5 \mathrm{mmol})$ solid was added to the above solution. Then the mixture was stirred and kept at $c a .75^{\circ} \mathrm{C}$ for $6 \mathrm{~h}$. The resultant solution was cooled and filtered, the orange crystals of poly[bis(3-bromo-2h y d r o x y b e n z a l d e hyde ) - 2 aminopyrimidinemagnesium(II)] were received from the filtrate in two weeks. Elemental analysis (\%) calcd. for $\mathrm{C}_{18} \mathrm{H}_{13} \mathrm{Br}_{2} \mathrm{MnN}_{3} \mathrm{O}_{4}$ : C, 39.27; H, 2.36; N, 7.64. Found (\%): C, 39.52; H, 2.19; N, 7.39.

\subsection{Synthesis of Pd@Mn (II) Coordination Polymer}

The Mn(II) coordination polymer-supported Pd catalysts were synthesized using impregnation method according to the procedures in the literature [29]. First, $0.0074 \mathrm{~g}$ of $\mathrm{Pd}\left(\mathrm{CH}_{3} \mathrm{COO}\right)_{2}$ were melted in $0.5 \mathrm{~mL}$ of ethanol. Then, the solution of $\mathrm{Pd}\left(\mathrm{CH}_{3} \mathrm{COO}\right)_{2}$ was added into $\mathrm{Mn}(\mathrm{II})$ coordination polymer $(0.070 \mathrm{~g})$. After sonicating for $1 \mathrm{~h}$, the suspension liquid was sustained at room temperature for $12 \mathrm{~h}$. The final homogenous mixture was further dried at 50 ${ }^{\circ} \mathrm{C}$ for $7 \mathrm{~h}$ in air dry oven.

\subsection{Crystal Structure Determination}

A suitable single crystal of poly[bis(3bromo-2-hydroxybenzaldehyde)-2-a minoPyrimidinemagnesium(II)] $(0.30 \mathrm{~mm} \times 0.20$ $\mathrm{mm} \times 0.10 \mathrm{~mm}$ ) was chosen to collect data on a Bruker Smart APEX CCD diffractometer with graphite-monochromated Mo- $K a$ radiation $(\lambda=$ $0.71073 \AA$ ) at $298(2) \mathrm{K}$. The structure was solved by direct method using SHELXL program [30] and refined by full-matrix least squares on $F^{2}$ by means of the program OLEX2 [31]. The crystallographic data of $\mathrm{Mn}$ (II) coordination polymer are summarized in Table 1.

\subsection{General Procedure for the Hydrogenation of 1,3-Butadiene}

The selective hydrogenation of 1,3butadiene was performed in a quartz fixed bed at the atmospheric pressure. $0.020 \mathrm{~g}$ of the catalyst mixed with $0.480 \mathrm{~g}$ quartz sand (40-80 mesh), and then packed into the reactor. Prior to catalysis, the catalyst was treated for at 50 ${ }^{\circ} \mathrm{C}$ for $1 \mathrm{~h}$ in a reducing environment with the 
$\mathrm{H}_{2}$ (99.999 \%) flow (at $10 \mathrm{~mL} / \mathrm{min}$ ). Then the reactants of 1.0 vol\% 1,3-butadiene in 99.0 vol\% $\mathrm{N}_{2}(13.0 \mathrm{~mL} / \mathrm{min})$ and $99.999 \mathrm{vol} \% \mathrm{H}_{2}(6.5$ $\mathrm{mL} / \mathrm{min}$ ) flowed through the Pd@Mn (II) coordination polymer catalyst bed. The effluent from the reactor was collected and analyzed using an online gas chromatography (GC-6890, Purkinje

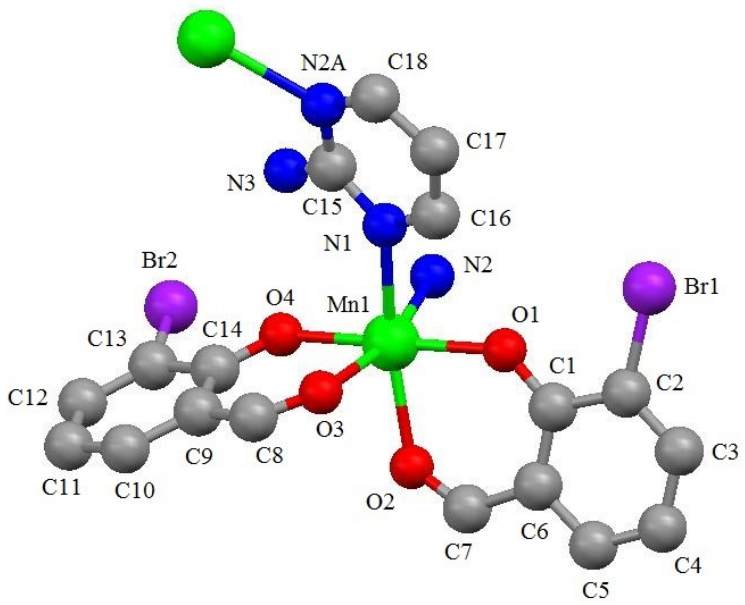

Figure 1. The asymmetric unit of Mn(II) coordination polymer 1 .
General Instrument Co., Ltd., China) equipped with a $\mathrm{Al}_{2} \mathrm{O}_{3}$ capillary column.

\section{Results and Discussion}

\subsection{Structural Description of Mn(II) Coordination Polymer}

Single-crystal X-ray diffraction shows that the $\mathrm{Mn}(\mathrm{II})$ coordination polymer 1 crystallizes in the monoclinic system with the $P 2_{1} / \mathrm{n}$ space group. The asymmetric unit of Mn(II) coordination polymer 1 is shown in Figure 1. The selected bond lengths $(\AA)$ and angles $\left(^{\circ}\right)$ for $\mathrm{Mn}$ (II) coordination polymer 1 are given in Table 2 . As shown in Figure 1, the asymmetric unit of $\mathrm{Mn}$ (II) coordination polymer is made up of one $\mathrm{Mn}$ (II) ion, one 2-aminopyrimidine ligand and two 3-bromo-2-hydroxybenzaldehyde ligands. Each $\mathrm{Mn}(\mathrm{II})$ ion is six-coordinated with two phenolic hydroxyl $\mathrm{O}$ atoms from two 3-bromo2-hydroxybenzaldehyde ligands (O1 and $\mathrm{O} 4)$, two formyl group $\mathrm{O}$ atoms from two 3-bromo-2hydroxybenzaldehyde ligands (O2 and $\mathrm{O} 3)$, and two $\mathrm{N}$ atoms from two 2-aminopyrimidine molecules (N1A and N2), and forms a distorted oc-

Table 1. Crystallographic data of Mn(II) coordination polymer 1.

\begin{tabular}{|c|c|}
\hline Empirical formula & $\mathrm{C}_{18} \mathrm{H}_{13} \mathrm{Br}_{2} \mathrm{MnN}_{3} \mathrm{O}_{4}$ \\
\hline Formula weight & 550.07 \\
\hline Temperature/K & $298(2)$ \\
\hline Crystal system & Monoclinic \\
\hline Space group & $P 2_{1} / n$ \\
\hline$a / \AA$ & $11.9818(6)$ \\
\hline$b / \AA$ & $7.4995(5)$ \\
\hline$c / \AA$ & $21.5342(9)$ \\
\hline$\alpha /{ }^{\circ}$ & 90 \\
\hline$\beta /^{\circ}$ & $91.650(6)$ \\
\hline$\gamma /{ }^{\circ}$ & 90 \\
\hline Volume/ $/ \AA^{3}$ & 1934.21(18) \\
\hline$Z$ & 4 \\
\hline$\rho_{\text {calc }}, \mathrm{mg} / \mathrm{mm}^{3}$ & 1.612 \\
\hline$\mu / \mathrm{mm}^{-1}$ & 4.844 \\
\hline$S$ & 1.036 \\
\hline$F(000)$ & 1076 \\
\hline Index ranges & $\begin{aligned}-14 & \leq h \leq 11 \\
-8 & \leq k \leq 7 \\
-22 & \leq l \leq 25\end{aligned}$ \\
\hline Reflections collected & 8235 \\
\hline$\theta /^{\circ}$ & $1.922-25.011$ \\
\hline Independent reflections & $3395[R(\mathrm{int})=0.0298]$ \\
\hline Data/restraints/parameters & $3395 / 0 / 241$ \\
\hline Goodness-of-fit on $F^{2}$ & 1.036 \\
\hline Refinement method & Full-matrix least-squares on $F^{2}$ \\
\hline Final $R$ indexes $[\mathrm{I}>=2 \sigma(I)]$ & $R_{1}=0.0318, w R_{2}=0.0563$ \\
\hline Final $R$ indexes [all data] & $R_{1}=0.0427, w R_{2}=0.0599$ \\
\hline Largest diff. peak/hole / e $\AA^{-3}$ & $0.583 /-0.544$ \\
\hline
\end{tabular}


tahedral coordination geometry. The bond angles around $\mathrm{Mn}$ (II) in the equatorial plane are O1-Mn1-O3 $\left(103.69(8)^{\circ}\right), \quad$ O3-Mn1-O4 $\left(82.01(8)^{\circ}\right)$, O4-Mn1-N2 $\left(83.99(8)^{\circ}\right)$, O1-Mn1-N2 $\left(90.57(9)^{\circ}\right)$, and the sum of the above bond angles is $360.26^{\circ}$, showing $\mathrm{O} 1, \mathrm{O} 3, \mathrm{O} 4, \mathrm{~N} 2$ and $\mathrm{Mn}(\mathrm{II})$ are coplanar. The $\mathrm{Mn}-\mathrm{O}$ and $\mathrm{Mn}-\mathrm{N}$ distances are 2.066(2) $\AA$ (Mn1-O1), 2.221(2) $\AA$ (Mn1-O2), 2.229(2) $\AA$ (Mn1-O3), 2.079(2) $\AA$ (Mn1-O4), 2.308(3) $\AA$ (Mn1-N1), and 2.310(2) $\AA$ (Mn1-N2), which are comparable to other $\mathrm{Mn}(\mathrm{II})$ coordination polymers [32,33]. The asymmetric unit of $\mathrm{Mn}$ (II) coordination polymer are connected by 2-aminopyrimidine to generate a 1D infinite chain (Figure 2). Finally, the isolated 1D chains assemble an extended $3 \mathrm{D}$ supramolecular framework via $\pi-\pi$ stacking interactions (Figure 3). It is worth mentioning that 2-aminopyrimidine as a bridge ligand

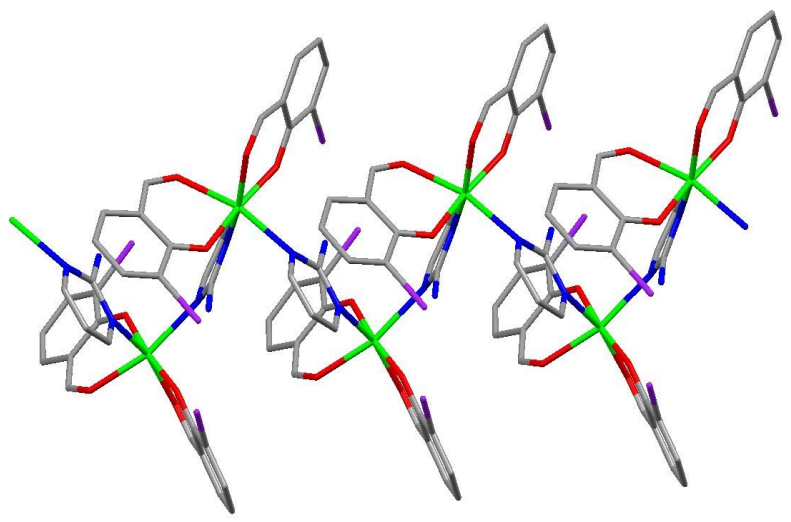

Figure 2. 1D chained structure of $\mathrm{Mn}$ (II) coordination polymer 1 . plays an important role in the formation of coordination polymer.

3.2 Synthesis Strategy of Pd@Mn(II) Coordination Polymer Catalyst

$\mathrm{Pd} @ \mathrm{Mn}(\mathrm{II})$ coordination polymer catalysts were synthesized using impregnation method. First, the solution of $\mathrm{Pd}\left(\mathrm{CH}_{3} \mathrm{COO}\right)_{2}$ was added into $\mathrm{Mn}$ (II) coordination polymer. After sonicating for $1 \mathrm{~h}$, the suspension was stored for 12 $\mathrm{h}$ at room temperature and dried in air dry oven at $50{ }^{\circ} \mathrm{C}$ for $7 \mathrm{~h}$. Finally, the catalysts were in-situ reduced at $50{ }^{\circ} \mathrm{C}$ for $1 \mathrm{~h}$ under $\mathrm{H}_{2}$ flow at rate of $10 \mathrm{~mL} / \mathrm{min}$ before catalysis in a quartz fixed bed. Liu et al. [29] prepared Pd/MIL-101(Cr) catalysts by impregnation using $\mathrm{Pd}\left(\mathrm{CH}_{3} \mathrm{COO}\right)_{2}$ as precursor, and followed by $\mathrm{H}_{2}$ reduction at $50{ }^{\circ} \mathrm{C}$ for $2 \mathrm{~h}$. Two obvious

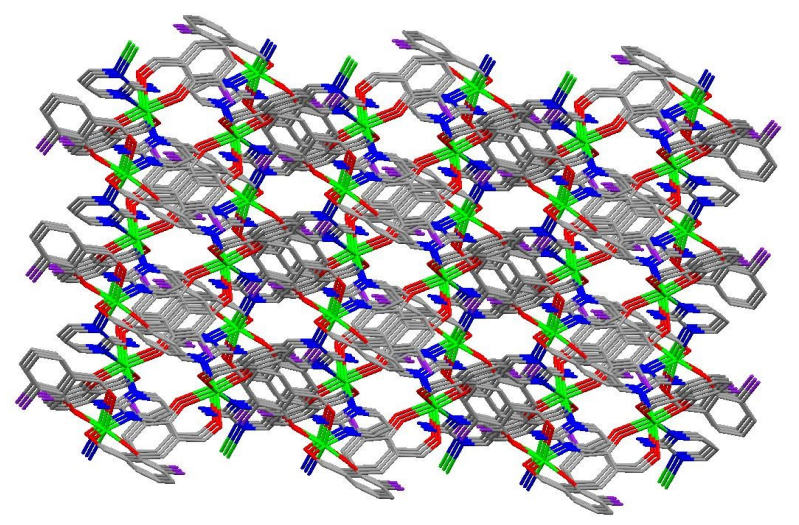

Figure 3. 3D network structure of $\mathrm{Mn}$ (II) coordination polymer 1 .

Table 2. Selected bond lengths $(\AA)$ and bond angles $\left(^{\circ}\right)$ for Mn(II) coordination polymer 1.

\begin{tabular}{cccc}
\hline Bond & $d$ & Angle & $\left({ }^{\circ}\right)$ \\
\hline Mn1-O1 & $2.066(2)$ & O4-Mn1-O1 & $173.73(9)$ \\
Mn1-O4 & $2.079(2)$ & O1-Mn1-O2 & $81.87(8)$ \\
Mn1-O2 & $2.221(2)$ & O2-Mn1-O4 & $96.36(9)$ \\
Mn1-O3 & $2.229(2)$ & O1-Mn1-O3 & $103.69(8)$ \\
Mn1-N1 & $2.308(3)$ & O4-Mn1-O3 & $82.01(8)$ \\
Mn1-N2 & $2.310(2)$ & O2-Mn1-O3 & $83.34(8)$ \\
C2-Br1 & $1.893(3)$ & O1-Mn1-N1 & $86.39(9)$ \\
C13-Br2 & $1.906(3)$ & O4-Mn1-N1 & $96.64(9)$ \\
C1-O1 & $1.297(4)$ & O2-Mn1-N1 & $162.41(9)$ \\
C7-O2 & $1.242(4)$ & O3-Mn1-N1 & $86.78(9)$ \\
C8-O3 & $1.232(4)$ & O1-Mn1-N2 & $90.57(9)$ \\
C14-O4 & $1.296(4)$ & O4-Mn1-N2 & $83.99(8)$ \\
C16-N1 & $1.340(4)$ & O2-Mn1-N2 & $103.82(8)$ \\
C15-N1 & $1.361(4)$ & O3-Mn1-N2 & $164.92(9)$ \\
C18-N2 & $1.338(4)$ & N1-Mn1-N2 & $89.30(9)$ \\
\hline
\end{tabular}


peaks were obtained in the Pd $3 \mathrm{~d}$ XPS spectra of $\mathrm{Pd} / \mathrm{MIL}-101(\mathrm{Cr})$ at the binding energy of $341.1 \mathrm{eV}$ and $335.6 \mathrm{eV}$ which were attributed to $\mathrm{Pd}^{0} 3 \mathrm{~d} 3 / 2$ and $\mathrm{Pd}^{0} 3 \mathrm{~d} 5 / 2$, respectively [29]. Taking into account that $\mathrm{Pd} @ \mathrm{Mn}$ (II) coordination polymer catalysts were prepared by a similar method to that of Pd/MIL-101(Cr), we may infer that Pd in the Pd@Mn(II) coordination polymer catalysts mainly exist in the metallic palladium $\left(\mathrm{Pd}^{0}\right)$.

\subsection{Catalytic Studies of 1,3-Butadiene Hydrogenation}

The conversions of 1,3-butadiene and product selectivity for the $\mathrm{Mn}$ (II) coordination polymer and Pd@Mn(II) coordination polymer catalysts are given in Figure 4 and Figure 5, respectively. The $\mathrm{Mn}$ (II) coordination polymer catalyst has very low catalytic activity with 1,3 butadiene conversion less than $1 \%$ toward the 1,3-butadiene hydrogenation because of lack of active sites. The Pd@Mn(II) coordination polymer catalyst shows the higher conversion than $\mathrm{Mn}$ (II) coordination polymer catalyst. The 1,3butadene conversions were $44.6 \%, 50.0 \%$, $61.3 \%, 63.7 \%$, and $64.1 \%$ on Pd@Mn (II) coordination polymer catalyst at $50{ }^{\circ} \mathrm{C}, 60^{\circ} \mathrm{C}, 70^{\circ} \mathrm{C}$, $80^{\circ} \mathrm{C}$, ad $90^{\circ} \mathrm{C}$, respectively. The 1,3 -butadiene conversion continuously increased with the increasing of reaction temperature from $50{ }^{\circ} \mathrm{C}$ to $70{ }^{\circ} \mathrm{C}$. At high temperature range $\left(70-90{ }^{\circ} \mathrm{C}\right)$, there is no much difference between the 1,3butadiene conversions. The Pd@Mn(II) coordination polymer catalyst shows the higher butene selectivities, the selectivities to total butenes are all close to $100 \%$ at $50-90{ }^{\circ} \mathrm{C}$. The selectivity of the Pd@Mn(II) coordination poly-

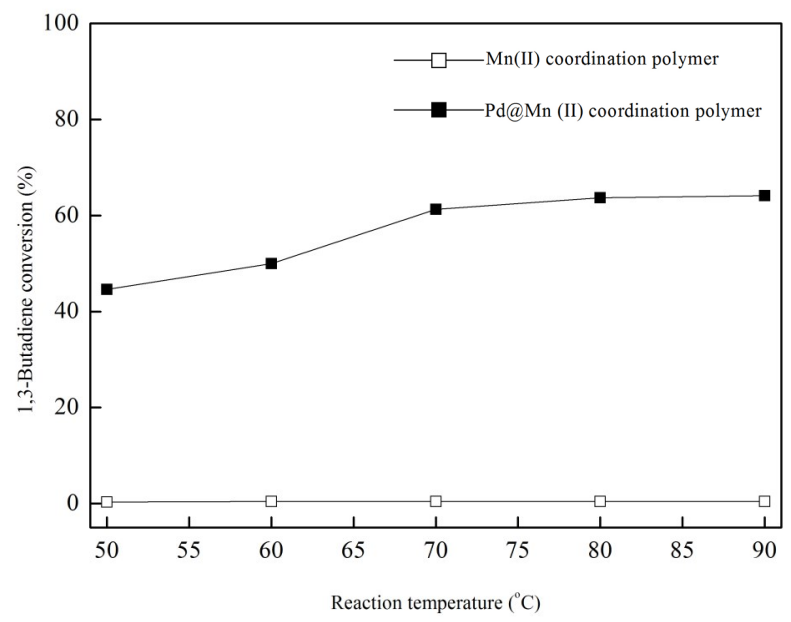

Figure 4. The conversions of 1,3-butadiene for $\mathrm{Mn}(\mathrm{II})$ coordination polymer and $\mathrm{Pd} @ \mathrm{Mn}(\mathrm{II})$ coordination polymer catalyst. mer catalyst to different isomers of butene showed the order 1-butene $>$ trans-2-butene $>$ cis-2-butene. The selectivities to 1-butene, trans-2-butene, and cis-2-butene are similar at $50-90{ }^{\circ} \mathrm{C}$, indicating that no isomerizations was occurred during the 1,3-butadiene hydrogenation reaction $[29,34,35]$.

\section{Conclusions}

In summary, we synthesized a new sixcoordinated $\mathrm{Mn}(\mathrm{II})$ coordination polymer, [ $\left.\mathrm{Mn}\left(\mathrm{L}_{1}\right)\left(\mathrm{L}_{2}\right)_{2}\right]$ n by 3 - bromo-2 hydroxybenzaldehyde, $\mathrm{NaOH}, \quad 2$ aminopyrimidine and manganese(II) acetate dihydrate. The Mn(II) coordination polymer displays a $1 \mathrm{D}$ chained structure by the bridge effect of 2-aminopyrimidine $\mathrm{N}$ atoms. The catalytic activities of Mn (II) coordination polymer and Pd@Mn (II) coordination polymer for hydrogenation of 1,3-butadiene have been investigated.

\section{Acknowledgments}

This project was supported by National Natural Science Foundation of China (No. 21171132) and Science Foundation of Weiyuan Scholars Innovation Team.

\section{References}

[1] Hou, R., Yu, W., Porosoff, M.D., Chen, J., Wang, T. (2014). Selective hydrogenation of 1,3-butadiene on PdANi bimetallic catalyst: From model surfaces to supported catalysts. Journal of Catalysis, 316, 1-10. DOI: 10.1016/j.jcat.2014.04.015

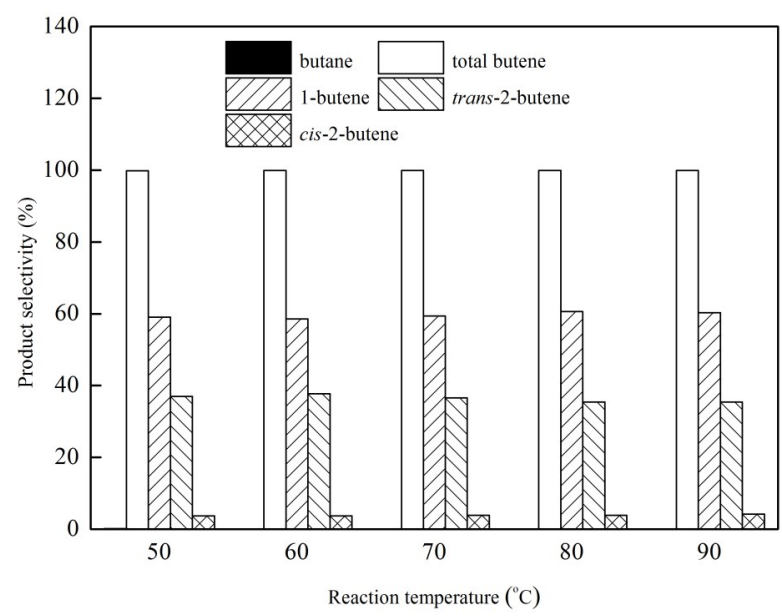

Figure 5. The product selectivity for Pd@Mn(II) coordination polymer catalyst. 
[2] Pattamakomsan, K., Ehret, E., Morfifin, F., Gélin, P., Jugnet, Y., Prakash, S.,Bertolini, J.C., Panpranot, J., Aires, F.J.C.S. (2011). Selective hydrogenation of 1,3-butadiene over $\mathrm{Pd}$ and Pd-Sn catalysts supported on different phases of alumina. Catalysis Today, 164: 28-33. DOI: 10.1016/j.cattod.2010.10.013

[3] Guo, Y., Yang, J., Zhuang, J., Sun, Z., Zhang, H., Yue, Y., Zhu, H., Bao, X., Yuan, P. (2020). Selectively catalytic hydrogenation of styrenebutadiene rubber over $\mathrm{Pd} / \mathrm{g}-\mathrm{C}_{3} \mathrm{~N}_{4}$ catalyst. $A p$ plied Catalysis A: General, 589, 117312117320. DOI: 10.1016/j.apcata.2019.117312

[4] Yuan, F., Yu, H.S., Yuan, C.M., Zhou, C.S., Li, F., Lu, Y.J., Ling, X.Y., Wang, J., Singh, A., Kumar, A. (2020). Structures and Photocatalytic Properties of two Mn(II)-based Coordination Polymers. Inorganica Chimica Acta, 499, 119189. DOI: 10.1016/j.ica.2019.119189

[5] Song, M., Mu, B., Huang, R.D. (2017). Syntheses, Structures, Electrochemistry and Catalytic Oxidation Degradation of Organic Dyes of Two New Coordination Polymers Derived From $\mathrm{Cu}(\mathrm{II})$ and $\mathrm{Mn}(\mathrm{II})$ and 1-(Tetrazo-5-yl)4-(triazo-1-yl)benzene. Journal of Solid State Che mistry, 246, 1-7. D O : 10.1016/j.jssc.2016.10.024

[6] Lymperopoulou, S., Papastergiou, M., Louloudi, M. (2014). Synthesis, Characterization, Magnetic and Catalytic Properties of a Ladder-Shaped Mn-II Coordination Polymer. European Journal of Inorganic Chemistry, 23, 3638-3644. DOI: 10.1002/ejic.201402419

[7] Liu, L., Huang, C., Zhang, L. (2015). $\mathrm{Co}(\mathrm{II}) / \mathrm{Mn}(\mathrm{II}) / \mathrm{Cu}(\mathrm{II})$ Coordination Polymers Based on Flexible 5,5-(Hexane-1,6-diyl)bis(oxy)diisophthalic Acid: Crystal Structures, Magnetic Properties, and Catalytic Activity. Crystal Growth and Design, 15, 2712-2722. DOI: 10.1021/acs.cgd.5b00016

[8] Yan, Q.Q., Li, B., Yong, G.P. (2021). Co(II) and $\mathrm{Mn}$ (II) Coordination Polymers: Ligand Functional and Positional Isomeric Effects, Structural Diversities, Luminescence Sensing and Magnetic Properties. Polyhedron, 194, 114918. DOI: 10.1016/j.poly.2020.114918

[9] Dutta, B., Maity, S., Ghosh, S., Sinha, C., Mir, M.H. (2019). An Acetylenedicarboxylatobridged Mn(ii)-based 1D Coordination Polymer: Electrochemical $\mathrm{CO}_{2}$ Reduction and Magnetic Properties. New Journal of Chemistry, 43, 5167-5172. D O I : 10.1039/C8NJ06387G

[10] Agarwal, R.N., Gupta, N.K. (2017). Integration of $\mathrm{Ag} / \mathrm{AgCl}$ and $\mathrm{Au}$ Nanoparticles into Isostructural Porous Coordination Polymers of $\mathrm{Ni}(\mathrm{II}), \mathrm{Co}(\mathrm{II})$ and $\mathrm{Mn}(\mathrm{II})$ : Magnetic Studies. RSC Advances, 7, 3870-3878. DOI: 10.1039/C6RA26642H
[11] Sehimi, H., Zid, M.F. (2018). A novel Mn(II) Oxalato-Bridged 2D Coordination Polymer: Synthesis, Crystal Structure, Spectroscopic, Thermal and Magnetic Properties. Journal of Chemical Sciences, 130, 25.

[12] Martina, L., Josefina, C., Fiorella, M., Carlo, C., Javier, M.R., Massimo, C. (2020). Tuneable Solvent Adsorption and Exchange by 1D Bispidine-based Mn(II) Coordination Polymers via Ligand Design. Dalton Transactions, 49, 13420-13429. DOI: 10.1039/D0DT02734K

[13] Liu, H., Guo, Z.F., Lv, H., Liu, X., Che, Y., Mei, Y.C., Bai, R., Chi, Y.H., Xing, H.Z. (2020). Visible-light-driven Self-coupling and Oxidative Dehydrogenation of Amines to Imines via a Mn(II)-based Coordination Polymer. Inorganic Chemistry Frontiers, 7, 10161025. DOI: 10.1039/C9QI01396B

[14] Wang, Y., Li, C. (2018). 3D Porous Mn(II) Coordination Polymer with Left-handed Helical Chains as Building Subunits: Selective Gas Adsorption of $\mathrm{CO}_{2}$ over $\mathrm{CH}_{4}$ and Anticancer Activity Evaluation. Inorganic Chemistry Communications, 96, 180-183. DOI: 10.1016/j.inoche.2018.08.020

[15] Etaiw, S..E.H., El-Bendary, M.M., Abdelazim, H. (2017). Synthesis, Characterization, and Biological Activity of Cd(II) and Mn(II) Coordination Polymers Based on Pyridine-2,6dicarboxylic Acid. Russian Journal of Coordination Chemistry, 43, 320-330. DOI: 10.1134/S1070328417050013

[16] Yang, H.L., Chen, F., He, X., Li, Y., Zhang, X.Q. (2018). Synthesis, Crystal Structure, Thermal Stability, Luminescence and Magnetic Property of a New $\mathrm{Mn}^{\mathrm{II}}$ Coordination Polymer. Chinese Journal of Structural Chemistry, 37, 1834-1841. DOI: 10.14102/j.cnki.0254-5861.2011-2145

[17] Li, S.D., Lu, L.P., Zhu, M.L., Feng, S.S., Su, F., Zhao, X.F. (2018). Exploring the Syntheses, Structures, Topologies, Luminescence Sensing and Magnetism of Zn(II) and Mn(II) Coordination Polymers Based on a Semirigid Tricarboxylate Ligand. CrystEngComm, 20, 5442-5456. DOI: 10.1039/C8CE00947C

[18] Zhai, L., Yang, Z.X., Zhang, W.W., Zuo, J.L., Ren, X.M. (2017). Surprisingly High Quantum Yield of Emission in a Fluorescent Coordination Polymer with Paramagnetic Mn(II) Ions. Dalton Transactions, 46, 1677916782. DOI: 10.1039/C7DT03909C

[19] Kan, W.Q., He, Y.C., Zhang, Z.C., Kan, Y.H., Wen, S.Z. (2019). Three Coordination Polymers Constructed from a Multidentate Ndonor Ligand, Polycarboxylate Anions and $\mathrm{Zn}(\mathrm{II}) / \mathrm{Ag}(\mathrm{I}) / \mathrm{Mn}(\mathrm{II})$ Ions: Synthesis, Structures, Characterization and $\mathrm{pH}$-dependent 
Photoluminescence. Journal of the Iranian Chemical Society, 16, 2021-2029. DOI: 10.1007/s13738-019-01672-9

[20] Hu, L., Lin, X.M., Lin, J., Zhang, R.Q., Zhang, D.L., Cai, Y.P. (2016). Structural Diversity of $\mathrm{Mn}(\mathrm{II}), \mathrm{Zn}(\mathrm{II})$ and $\mathrm{Pb}(\mathrm{II})$ Coordination Polymers Constructed from Isomeric Pyridylbenzoate N-oxide Ligands: Structures and Electrochemical Properties. CrystEngComm, 48, 9307-9315. DOI: 10.1039/C6CE02071B

[21] Xu, B.W., Niu, R.J., Liu, Q., Yang, J.Y., Zhang, W.H., Young, D.J. (2020). Similarities and Differences Between $\mathrm{Mn}(\mathrm{II})$ and $\mathrm{Zn}(\mathrm{II})$ Coordination Polymers Supported by Porphyrin-based Ligands: Synthesis, Structures and Nonlinear Optical Properties. Dalton Transactions, 49, 12622-12631. DOI: 10.1039/D0DT02450C

[22] Tan, J.T., Pan, M., Li, S., Yang, X.W. (2018). Two New Cd(II) Coordination Polymer Based on Biphenyl-3, 3', 5, 5'-tetracarboxylic acid. Inorganic Chemistry Communications, 87, 36-39. DOI: 10.1016/j.inoche.2017.11.017

[23] Wang, L.H., Wang, X., Tai, X.S. (2017). Synthesis, Crystal Structure and Catalytic Activity of a 1D Chained Ca(II) Coordination Polymer with 3,5-Bis(4-pyridylmethoxy)benzoate Ligand. Crystals, 7, 72. DOI: 10.3390/cryst7030072

[24] Wang, L.H., Liang, L., Wang, X. (2017). Synthesis, Structural Characterization and Catalytic Activity of A $\mathrm{Cu}(\mathrm{II})$ Coordination Polymer Constructed from 1,4-Phenylenediacetic Acid and 2,2'-Bipyridine. Bulletin of Chemical Reaction Engineering \& Catalysis, 12, 113118. DOI: $10.9767 /$ bcrec.12.1.735.113-118

[25] Wang, L.H., Liang, L., Li, P.F. (2017). Synthesis, Crystal Structure, Catalytic Properties, and Luminescent of a Novel Eu(III) Complex Material with 4-Imidazolecarboxaldehydepyridine-2-carbohydrazone. Bulletin of Chemical Reaction Engineering \& Catalysis, 12, 185-190. DOI: 10.9767/bcrec.12.2.764.185-190

[26] Tai, X.S., Li, P.F., Liu, L.L. (2018). Preparation, Characterization, and Catalytic Property of a $\mathrm{Cu}(\mathrm{II})$ Complex with 2Carboxybenzaldehyde-p-Toluenesulfonyl Hydrazone Ligand. Bulletin of Chemical Reaction Engineering \& Catalysis, 13, 7-13. DOI: 10.9767/bcrec.13.1.1012.7-13

[27] Tai, X.S., Guo, Q.Q., Li, P.F., Liu, L.L. (2018). A Ca(II) Coordination Polymer of 2Carboxybenzaldehyde: Synthesis, Crystal Structure, and Catalytic Activity in Oxidation of Benzyl Alcohol. Crystals, 8, 150. DOI: $10.3390 /$ cryst 8040150
[28] Tai, X.S., Li, P.F., Liu, L.L. (2018). Synthesis, Crystal Structure and Catalytic Activity of a Calcuim(II) Complex with 4-Formylbenzene1,3-disulfonate-isonicotinic Acid Hydrazone. Bulletin of Chemical Reaction Engineering \& Catalysis, 13, 429-435. DOI: 10.9767/bcrec.13.3.1961.429-435

[29] Liu, L.L., Zhou, X.J., Guo, L.X., Yan, S.J., Li, Y.J., Jiang, S., Tai, X.S. (2020). Bimetallic $\mathrm{Au}-\mathrm{Pd}$ Alloy Nanoparticles Supported on MIL-101(Cr) as Highly Efficient Catalysts for Selective Hydrogenation of 1,3-Butadiene. RSC Advances, 10, 33417-33427. DOI: 10.1039/D0RA06432G

[30] Sheldrick, G.M. (2015). Crystal Structure Refinement with SHELXL. Acta Crystallograph-

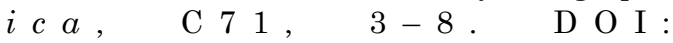
$10.1107 / \mathrm{S} 2053229614024218$

[31] Dolomanov, O.V., Bourhis, L.J., Gildea, R.J., Howard, J.A.K., Puschmann, H. (2009). OLEX2: A Complete Structure Solution, Refinement and Analysis Program. Journal of Applied Crystallography, 42, 339-341. DOI: 10.1107/S0021889808042726

[32] Yin, J., Zhang, F.J., Tai, X.S. (2021). The Crystal Structure of Trans-tetraaqua-bis(4acetylphenoxyacetato- $\mathrm{K}^{1} O$ ) manganese(II), $\mathrm{C}_{20} \mathrm{H}_{26} \mathrm{O}_{12} \mathrm{Mn}$. Zeitschrift für Kristallographie. New Crystal Structures, 236, 45-46. DOI: 10.1515/ncrs-2020-0467

[33] Wang, L.H., Li, P.F. (2018). Synthesis, Structure, and Catalytic Activity of A New Mn(II) Complex with 1,4-Phenylenediacetic Acid and 1,10-Phenanthroline. Bulletin of Chemical Reaction Engineering \& Catalysis, 13, 1-6. DOI: 10.9767/bcrec.13.1.975.1-6

[34] Liu, L.L., Tai, X.S., Zhou, X.J., Liu, L., Zhang, Y., Ding, L.Y., Ahang, Y.C., (2020). Au-Pt Bimetallic Nanoparticle Catalysts Supported on UiO-67 for Selective 1,3-Butadiene Hydrogenation. Journal of the Taiwan Institute of Chemical Engineers, 114, 220-227. DOI: 10.1016/j.jtice.2020.09.025

[35] Lozano-Mart'ın, M.C., Castillejos, E., Bachiller-Baeza, B., Rodr'iguez-Ramos, I., Guerrero-Ruiz, A. (2015). Selective 1,3Butadiene Hydrogenation by Gold Nanoparticles on Novel Nano-carbon Materials. Catalysis Today, 249, 117-126. DOI: 10.1016/j.cattod.2014.11.023 